\title{
The utility of fat mass index vs. body mass index and percentage of body fat in the screening of metabolic syndrome
}

Pengju Liu ${ }^{1}$, Fang Ma ${ }^{1,3^{*}}$, Huiping Lou ${ }^{2}$ and Yanping Liu ${ }^{1}$

\begin{abstract}
Background: It has been well documented that obesity is closely associated with metabolic syndrome (MetS). Although body mass index (BMI) is the most frequently used method to assess overweightness and obesity, this method has been criticized because BMI does not always reflect true body fatness, which may be better evaluated by assessment of body fat and fat-free mass. The objective of this study was to investigate the best indicator to predict the presence of MetS among fat mass index, BMI and percentage of body fat (BF \%) and determine its optimal cut-off value in the screening of MetS in practice.
\end{abstract}

Methods: A cross-sectional study of 1698 subjects (aged 20-79 years) who participated in the annual health check-ups was employed. Body composition was measured by bioelectrical impedance analysis (BIA). Fat mass index (FMI) was calculated. Sex-specific FMl quartiles were defined as follows: Q1: <4.39, Q2:4.39- < 5.65, Q3:5.65- < 7.03, Q4: $\geq 7.03$,in men; and Q1:<5.25, Q2:5.25-<6.33, Q3:6.33-<7.93,Q4: 27.93 , in women. MetS was defined by National Cholesterol Education Program/Adult Treatment Panel III criteria. The association between FMl quartiles and MetS was assessed using Binary logistic regression. Receiver operating curve $(\mathrm{ROC})$ analysis was used to determine optimal cutoff points for $\mathrm{BMI}, \mathrm{BF} \%$ and $\mathrm{FMl}$ in relation to the area under the curve(AUC),sensitivity and specificity in men and women.

Results: The adjusted odds ratios $(95 \% \mathrm{Cl})$ for the presence of MetS in the highest FMI quartile versus lowest quartile were 79.143(21.243-294.852) for men $(P<0.01)$ and 52.039(4.144-653.436) for women ( $P<0.01$ ) after adjusting age, BMl, $\mathrm{BF} \%, \mathrm{TC}, \mathrm{LDL}, \mathrm{CRP}$, smoking status and exercise status, and the odds ratios were $9.166(2.157-38.952)$ for $\operatorname{men}(P<0.01)$ and 25.574(1.945-336.228) for women $(P<0.05)$ when WC was also added into the adjustment. It was determined that BMI values of 27.45 and $23.85 \mathrm{~kg} / \mathrm{m}^{2}, \mathrm{BF} \%$ of $23.95 \%$ and $31.35 \%$ and $\mathrm{FMl}$ of 7.00 and $7.90 \mathrm{~kg} / \mathrm{m}^{2}$ were the optimal cutoff values to predict the presence of MetS among men and women according to the ROC curve analysis. Among the indicators used to predict MetS, FMI was the index that showed the greatest area under the ROC curve in both sexes.

Conclusions: Higher FMl levels appear to be independently and positively associated with the presence of MetS regardless of $\mathrm{BMI}$ and $\mathrm{BF} \%$. FMl seems to be a better screening tool in prediction of the presence of metabolic syndrome than BMl and percentage of body fat in men and women.

Keywords: Metabolic syndrome X, Body composition, Fat mass index, Body mass index, Percentage of body fat, Screening

\footnotetext{
* Correspondence: mafang219@126.com

${ }^{1}$ Department of Clinical Nutrition, Peking Union Medical College Hospital,

China Academic Medical Science and Peking Union Medical College, Beijing 100730, China

${ }^{3}$ No.1 ShuaiFuyuan, Wang Fujing ST, Dongcheng District, Beijing 100730, China

Full list of author information is available at the end of the article
} 


\section{Background}

Obesity is one of basic clinical conditions of metabolic syndrome (MetS), which is a cluster of risk factors for cardiovascular disease (CVD). The clustering of factors includes overweight/obesity, hyperinsulinemia, hypertension, hyperlipidemia, fasting hyperglucose or type 2 diabetes mellitus, and obesity (particularly central obesity) plays a central role in the MetS [1]. The growing prevalence of overweight and obesity are established risk factors for the metabolic syndrome [2].

Although body mass index (BMI) is the most frequently used method to assess overweightness and obesity, this method has been criticized because BMI does not always reflect true body fatness [3-6] and has some limitations in assessing the risk of obesity-related diseases in persons with low muscle and high body fat [7], and in individuals with increased body fat and normal BMI. A recent study [8] reported that normal weight obesity was associated with MetS and insulin resistance, and suggested that clinical assessment of excess body fat in normal-BMI individuals should begin early in life. It seems that true body fatness may be better evaluated by assessment of body fat and fat-free mass [9]. Therefore, much research has recently examined the potential role of body composition measurements [7,10-14].

Until now, bioelectrical impedance analysis (BIA) has been considered as the simplest, most reproducible and least expensive method for body composition evaluation in clinical practice, and it showed high accuracy and excellent correlation with dual-energy X-ray absorptiometry(DXA) in assessing BF\% [15-17]. Therefore, BIA is considered the most cost-effective and feasible replacement for DXA in assessing body composition. BF\% has been most commonly used in practice. However, the accuracy of $\mathrm{BF} \%$ measurements is dependent on height and cannot be evaluated independently from fat free mass (FFM) [18]. Moreover, percentage of body fat does not adjust appropriately for body size, although height has recently been reported as an independent risk factor for CVD [19]. Therefore, both fat mass and fat-free mass should be normalized for body size [20]. Acknowledging such a problem, VanItallie et al. proposed a fat-free mass index (FFMI; FFM $/$ height $^{2}$ ) and a fat mass index (FMI; FMI $/$ height $^{2}$ ) that considers an individual's height [21]. FMI and FFMI are calculated by dividing fat mass (FM) and fat-free mass (FFM) by the square of height. These calculated body fat indices eliminate the differences of the BF\% associated with one's height, can independently evaluate body fatness from changes in FFM, and therefore, could be a useful measure of obesity [22-24].

The objective of this study was to investigate the best indicator to predict the presence of MetS among fat mass index, BMI and percentage of body fat (BF\%) and determine its optimal cut-off value in the screening of MetS in practice.

\section{Methods}

Subjects in the study were enrolled from 2179 people who participated in the annual health check-up in the Department of Medical examination center, Peking Union Medical College Hospital, China Academic Medical Science and Peking Union Medical College, China, in 2011(from January to July). A standard questionnaire was used by trained physicians to collect related information including age, sex, physical activity, smoking, and medication use, and then routine physical examinations were performed to all subjects, and two blood pressure recordings were obtained from the right arm of subjects in a sitting position after $30 \mathrm{~min}$ of rest; Diabetes or hypertension were recorded if a participant gave a positive answer to the question: Have you ever been diagnosed by a physician as diabetes or hypertension? Smoking status was categorized as current smokers and non-smokers (nonsmokers or stop smoking for at least 6 months). People who exercised three or more times a week for $>30$ minutes were categorized as the regular exercise group, and those who exercised less than three times a week were considered the non-regular group. The exclusion criteria were as the follows: 1) with the evidence of cancer, renal, or hematological disease; 2) a medication history of corticosteroids in the previous 6 months; 3) those who were going on a weight-loss program or weight loss $\geq 5 \%$ of body weight within 12 months; 4) people who refused to participate in this study.

Finally, 1698 subjects aged $20 \sim 79$ years were enrolled in the study (1105 men and 593 women). All of the study procedures were approved by the Ethics Committee of Peking Union Medical College Hospital, China Academic Medical Science. All subjects provided informed consent to participate in the study.

\section{Anthropometric measurements}

Anthropometric measurements of individuals wearing light clothing and without shoes were conducted by well-trained examiners. Height was measured to the nearest $0.1 \mathrm{~cm}$ with a portable stadiometer. Weight was measured in an upright position to the nearest $0.1 \mathrm{~kg}$ with a calibrated scale. Body mass index was calculated by dividing weight $(\mathrm{kg})$ by height squared $\left(\mathrm{m}^{2}\right)$. Waist circumference measurements were taken at the end of normal expiration to the nearest $0.1 \mathrm{~cm}$, measuring from the midway between the lower borders of the rib cage and the iliac crest.

\section{Body composition measurements}

Fat mass, percent body fat were measured by multifrequency bioelectric impedance analysis (multi-frequency bioelectric impedance analyzer Inbody 720, 8 contact point, 5, 50, 250, and $500 \mathrm{kHz}$,Biospace Co. Ltd., Seoul, Korea). Four electrodes were placed on the palm and thumb of both hands, and four on the anterior and posterior aspects 
of the soles of both feet. Then fat mass index was calculated by dividing the each subject's fat mass $(\mathrm{kg})$ by square of his/her height (m). FMI levels were divided into separate quartiles for men and women. Sex-specific FMI quartiles were used as follows: Q1: $<4.39$, Q2: $4.39-<5.65$, Q3: 5.65-<7.03, Q4: $\geq 7.03$, in men; and Q1: $<5.25$, Q2: 5.25- <6.33, Q3: 6.33- < 7.93, Q4: $\geq 7.93$, in women.

\section{Biochemical measurements}

Blood sample were collected from the subjects' peripheral vein in the morning after a fasting period of 10-12 h. the samples were immediately centrifuged at $4^{\circ} \mathrm{C}$, and plasma for assays of lipid profile (including total cholesterol (TC), triglyceride (TG), low-density-lipoprotein cholesterol (LDL$\mathrm{C}$ ), and high-density-lipoprotein cholesterol (HDL-C)), fasting blood glucose (FBG), C-reactive protein (CRP), using an automated analyzer (Olympus AU5400, Japan).

Definition of metabolic syndrome and overweight/obesity The MetS was defined using the updated National Cholesterol Education Program/Adult Treatment Panel III criteria (NCEP-ATP III) [25] for Asian Americans as having $\geq 3$ of the following components: waist circumference $\geq 90 \mathrm{~cm}$ for men or $\geq 80 \mathrm{~cm}$ for women; triglycerides $\geq 1.7 \mathrm{mmol} / \mathrm{L}$; HDL cholesterol $<1.03 \mathrm{mmol} / \mathrm{L}$ for men or $<1.30 \mathrm{mmol} / \mathrm{L}$ for women; blood pressure $\geq 130$ / $85 \mathrm{~mm} \mathrm{Hg}$ or current use of antihypertensive medications; or fasting glucose $\geq 5.6 \mathrm{mmol} / \mathrm{L}$, type 2 diabetes mellitus previously diagnosed by a physician, or current use of antidiabetic medications. Overweight and obesity were defined as a participant with body mass index (BMI) $\geq 24$ and $<28 \mathrm{~kg} / \mathrm{m}^{2}$, and BMI $\geq 28 \mathrm{~kg} / \mathrm{m}^{2}$ respectively, according to the cut-off point [26] for Chinese adults, or BF\% $\geq 25 \%$ (men) and BF\% $\geq 30 \%$ (women).

\section{Statistical analysis}

Statistical analysis were performed separately according to sex by using the Statistical Package for Social Science (SPSS version 11.5, Chicago, IL, USA) continuous variables were expressed as means $\pm \mathrm{SD}$, whereas categorical variables were represented by frequency and percentage. The differences between two sexes and two groups (Mets group and non- Mets group) were examined by ttest for continuous variables and by $X^{2}$ test for categorical variables, respectively. The association between the sex-specific fat mass index quartile and metabolic syndrome were tested using Binary Logistic regression analysis, and we calculated the unadjusted and adjusted odds ratio (ORs) using the lowest quartile as the reference. Receiver operating curve (ROC) analysis were used to determine optimal cutoff points for BMI, FMI and BF\% in relation to the area under the curve (AUC), sensitivity and specificity in men and women. The values of FMI, $\mathrm{BMI}$ and $\mathrm{BF} \%$ that resulted in maximizing the Youden index (sensitivity + specificity-1) were defined as optimal. $\mathrm{P}<0.05$ was considered significant for all the statistical analysis.

\section{Results}

The characteristics of the 1698 participants are summarized in Table 1 . In this study population, 232 men (21.00\%) and 109 women (18.40\%) were diagnosed with

Table 1 The general characteristics according to sex

\begin{tabular}{lccc}
\hline Variables & Men $(\mathbf{n}=\mathbf{1 1 0 5})$ & Women(n= 593) & P value \\
\hline Age(yr) & $46.96 \pm 8.46$ & $46.45 \pm 10.79$ & 0.319 \\
Body mass index(kg/m2) & $26.01 \pm 3.02$ & $23.31 \pm 3.36$ & $6.74 \pm 2.25$ \\
Fat mass index(kg/m2) & $5.78 \pm 2.12$ & $28.11 \pm 5.91$ & 0.000 \\
Percentage of body fat(\%) & $21.59 \pm 6.11$ & $77.81 \pm 6.60$ & 0.000 \\
Waist circumference(cm) & $84.67 \pm 7.35$ & $124.83 \pm 21.63$ & 0.000 \\
Systolic blood pressure(mmHg) & $124.24 \pm 17.84$ & $73.17 \pm 11.1$ \\
Diastolic blood pressure(mmHg) & $77.34 \pm 11.95$ & $4.79 \pm 0.90$ & 0.000 \\
Total cholesterol(mmol/L) & $4.95 \pm 0.91$ & $1.29 \pm 0.90$ & 0.565 \\
Triglyceride(mmol/L) & $2.03 \pm 1.43$ & $1.38 \pm 0.31$ & 0.000 \\
High-density-lipoprotein cholesterol(mmol/L) & $1.12 \pm 0.25$ & $2.94 \pm 0.78$ \\
Low-density-lipoprotein cholesterol(mmol/L) & $3.12 \pm 0.79$ & $5.09 \pm 0.89$ \\
Fasting blood glucose(mmol/L) & $5.51 \pm 1.25$ & $1.38 \pm 1.83$ \\
C-reactive protein(mg/L) & $1.84 \pm 2.10$ & $18.40 / 109$ & 0.001 \\
Prevalence of MetS (\%/n) & $21.00 / 232$ & $19.2 / 114$ & 0.000 \\
Percentage of Smokers (\%/n) & $38.40 / 424$ & $42.7 / 253$ & 0.000 \\
Percentage of regular exerciser $(\% / \mathrm{n})$ & $32.3 / 357$ & 0.000 \\
\hline
\end{tabular}


Table 2 The descriptive characteristics of participantsts with and without MetS in both sexes

\begin{tabular}{|c|c|c|c|c|c|c|}
\hline \multicolumn{4}{|c|}{ Men } & \multicolumn{3}{|c|}{ Women } \\
\hline Variables & MetS & non-MetS & $P$ value & MetS & non-MetS & $P$ value \\
\hline Age(yr) & $46.98 \pm 7.38$ & $46.96 \pm 8.73$ & 0.971 & $52.25 \pm 9.56$ & $45.15 \pm 10.63$ & 0.000 \\
\hline $\mathrm{BMI}\left(\mathrm{kg} / \mathrm{m}^{2}\right)$ & $29.49 \pm 2.59$ & $25.09 \pm 2.39$ & 0.000 & $27.33 \pm 3.38$ & $22.41 \pm 2.61$ & 0.000 \\
\hline WC(cm) & $93.84 \pm 6.28$ & $82.23 \pm 5.43$ & 0.000 & $85.94 \pm 6.68$ & $75.98 \pm 5.02$ & 0.000 \\
\hline BF(\%) & $27.88 \pm 4.67$ & $19.92 \pm 5.31$ & 0.000 & $34.11 \pm 4.58$ & $26.76 \pm 5.30$ & 0.000 \\
\hline $\mathrm{FMI}\left(\mathrm{kg} / \mathrm{m}^{2}\right)$ & $8.33 \pm 1.87$ & $5.10 \pm 1.60$ & 0.000 & $9.46 \pm 2.22$ & $6.12 \pm 1.75$ & 0.000 \\
\hline $\mathrm{SBP}(\mathrm{mmHg})$ & $129.15 \pm 17.76$ & $122.93 \pm 17.64$ & 0.000 & $138.82 \pm 20.65$ & $121.69 \pm 20.60$ & 0.000 \\
\hline $\mathrm{DBP}(\mathrm{mmHg})$ & $84.00 \pm 11.48$ & $75.57 \pm 11.45$ & 0.000 & $79.72 \pm 12.39$ & $71.69 \pm 10.36$ & 0.000 \\
\hline $\mathrm{TC}(\mathrm{mmol} / \mathrm{L})$ & $4.94 \pm 0.91$ & $4.95 \pm 0.91$ & 0.921 & $4.92 \pm 1.01$ & $4.76 \pm 0.87$ & 0.118 \\
\hline $\mathrm{TG}(\mathrm{mmol} / \mathrm{L})$ & $3.19 \pm 2.21$ & $1.73 \pm 0.98$ & 0.000 & $2.24 \pm 1.36$ & $1.08 \pm 0.58$ & 0.000 \\
\hline $\mathrm{HDL}(\mathrm{mmol} / \mathrm{L})$ & $0.99 \pm 0.21$ & $1.16 \pm 0.25$ & 0.000 & $1.12 \pm 0.22$ & $1.44 \pm 0.30$ & 0.000 \\
\hline LDL(mmol/L) & $2.99 \pm 0.89$ & $3.16 \pm 0.76$ & 0.008 & $3.03 \pm 0.83$ & $2.93 \pm 0.76$ & 0.238 \\
\hline $\mathrm{FBG}((\mathrm{mmol} / \mathrm{L}))$ & $6.42 \pm 1.77$ & $5.27 \pm 0.93$ & 0.000 & $5.84 \pm 1.67$ & $4.92 \pm 0.43$ & 0.000 \\
\hline $\mathrm{CRP}(\mathrm{mg} / \mathrm{L})$ & $2.60 \pm 2.37$ & $1.64 \pm 1.98$ & 0.000 & $2.02 \pm 1.88$ & $1.23 \pm 1.79$ & 0.000 \\
\hline Current smokers(\%) & 40.10 & 37.90 & 0.545 & 21.1 & 18.8 & 0.582 \\
\hline Regular exercise(\%) & 25.00 & 34.20 & 0.007 & 45.9 & 41.9 & 0.454 \\
\hline
\end{tabular}

MetS by NCEP-ATP III criteria. The mean of many parameters (including BMI, WC, DBP, TC, TG, LDL, FBG, $\mathrm{CRP}$ ) and the percentage of smokers were significantly higher in men than in women $(P<0.001)$, but the mean $\mathrm{HDL}, \mathrm{BF} \%, \mathrm{FMI}$, and the percentage of regular exerciser were significantly lower in men than in women $(P<$ $0.001)$. No significant differences in the mean of age or SBP and in the prevalence of MetS were found between men and women.

In MetS group for both sexes (Table 2), variables including BMI, WC, WHtR, WHR, BF\%, FMI, SBP, DBP, TG, FBG, and CRP were significantly higher than those in non- MetS group $(P<0.001)$, but HDL was significantly lower than that in non- MetS group $(P<0.001)$. No significant differences in the mean of TC or the percentage of current smokers were found between MetS group and non- MetS group for both sexes. In addition, percentage of regular exercise $(P=0.008)$ and mean LDL $(P=0.007)$ in MetS group of men were significantly lower than in non- MetS group, and mean age in MetS group of women was higher than in non- MetS group $(P<0.001)$.

\section{The prevalence of MetS according to FMI quartiles}

The prevalence of MetS in each FMI quartile level were $1.44 \%, 3.24 \%, 13.10 \%$ and $66.55 \%$ for men, and $0.70 \%$, $2.70 \%, 14.86$ and 55.41 for women, respectively. The prevalence of MetS significantly increased in $3^{\text {rd }}$ and $4^{\text {th }}$ FMI quartiles for both men and women $(\mathrm{P}<0.001$ for both sexes) (Figure 1).
Odds ratio and $95 \%$ confidence intervals for the presence of MetS using the lowest FMI quartile as the reference Table 3 shows the risk of MetS according to the FMI quartiles. After adjustment for age, BMI, BF\%, TC, LDL, CRP, smoking status and exercise status, the 3rd and 4th FMI quartiles had significantly higher Odds ratio for metabolic syndrome than the lowest quartile in both sexes. The adjusted OR (95\% CI) for the presence of metabolic syndrome in subjects with the highest FMI quartile was 52.039 (4.144-653.436) for women and 79.143 (21.243-294.852) for men, as compared to the subjects with the lowest FMI quartile. When WC was added as a additional adjusted factor into regression analysis, the $3^{\text {rd }}$ and $4^{\text {th }}$ quartiles of FMI for men and the $4^{\text {th }}$ quartile of FMI for women also had significantly

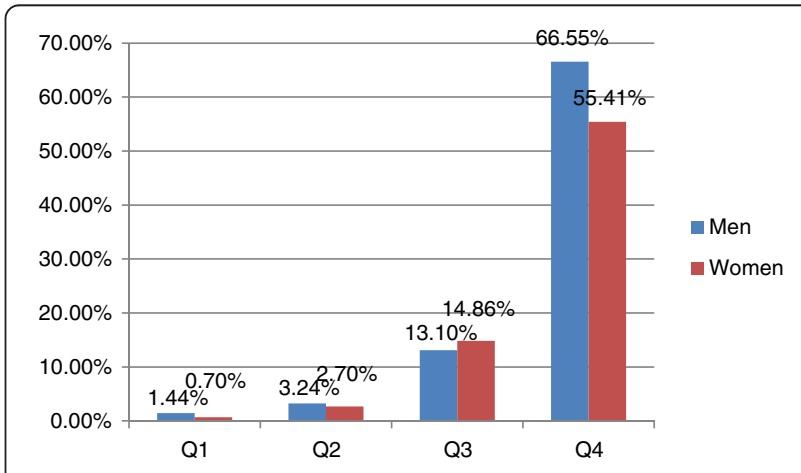

Figure 1 Prevalence of metabolic syndrome (MetS) according to the FMI quartiles. 
Table 3 Odds ratio and $95 \%$ confidence intervals for the presence of MetS according to the FMI quartiles in men and women

\begin{tabular}{|c|c|c|c|c|}
\hline \multicolumn{5}{|c|}{ Odds ratio( $95 \%$ confidence interval) } \\
\hline Gender & FMI $\left(\mathrm{kg} / \mathrm{m}^{2}\right)$ & Unadjusted & Adjusted* & Adjusted \$ \\
\hline \multirow[t]{4}{*}{ Women } & Quartile $1(<5.25)$ & 1 & 1 & 1 \\
\hline & Quartile 2(5.25-6.33) & $4.083(0.451-36.975)$ & $2.722(0.288-25.749)$ & $3.127(0.340-30.464)$ \\
\hline & Quartile 3(6.33-7.93) & $25.465(3.385-191.583)^{\wedge}$ & 10.584(1.190-94.111)\# & 8.397(0.917-76.883) \\
\hline & Quartile 4(>7.93) & $182.636(24.887-1340.296)^{\wedge}$ & $52.039(4.144-653.436) \&$ & 25.574(1.945-336.228)\# \\
\hline \multirow[t]{4}{*}{ Men } & Quartile 1(<4.39) & 1 & 1 & 1 \\
\hline & Quartile 2(4.39-5.65) & $2.283(0.695-7.504)$ & $1.329(0.380-4.650)$ & $1.305(0.372-4.584)$ \\
\hline & Quartile 3(5.65-7.03) & $10.280(3.607-29.304)^{\wedge}$ & 4.698(1.480-14.909)\# & 3.860(1.203-12.392)\# \\
\hline & Quartile 4(>7.03) & $135.758(49.031-375.890)^{\wedge}$ & $79.143(21.243-294.852) \&$ & $9.166(2.157-38.952) \&$ \\
\hline
\end{tabular}

*Adjusted for age, smoking status, exercise status, total cholesterol, low-density-lipoprotein cholesterol, percentage of body fat and C-reactive protein. \$ added WC into * model; $\# P<0.05 ; \& P<0.01 ; \wedge P<0.001$.

higher Odds ratio for metabolic syndrome than the lowest quartile.

Other parameters' odds ratio and $95 \%$ confidence intervals for the presence of MetS using the lowest FMI quartile as the reference

According to Binary logistic regression analysis, besides high FMI level, overall overweight or obesity, and elevated CRP level, were independently associated with MetS in men $\left(X^{2}=51.032, P<0.001\right)$, whereas in women subjects, age, overall overweight or obesity, and elevated CRP level were independently associated with MetS $\left(X^{2}=36.327\right.$, $P<0.001$ ). Odds ratio of MetS in both sexes were shown in Table 4.

\section{ROC curve analysis of MetS-associated indicators to predict MetS}

The areas under ROC curve, the cutoff values, and the most appropriate sensitivities and specificities of the indicators are presented in Table 5.

As shown in Figure 2 and 3, which include the ROC curves of BMI, BF\%, and FMI, It can be observed that the line referring to the FMI possesses the largest projection for the upper left corner of the curve in the three parameters in both sexes $\left(\mathrm{AUC}_{\mathrm{FMI}}=\mathrm{AUC}_{\mathrm{BMI}}\right.$, in women $)$, which indicates its best predictive potential among the the parameters.

\section{Discussion}

Metabolic syndrome is associated with the development of diabetes, cardiovascular disease, which is the leading cause of mortality worldwide [27] and epidemical in China and other economically developing countries in recent decades [28]. In addition, MetS was associated with arteral stiffness, which was a cardiovascular outcome of MetS [29]. Therefore, it is very important to develop an effective screening tool of metabolic syndrome in practice in China.

To our best knowledge, this is the first large crosssectional study that examined the association of fat mass index quartiles (by BIA) and metabolic syndrome and determine the optimal cut-off values of fat mass index in prediction of metabolic syndrome in practice in Chinese population.

In this study, BMI, BF\% and FMI were used to screen the presence of metabolic syndrome. One study [30] concluded that the BMI, waist circumference and waistto-height ratio can predict the presence of multiple metabolic risk factors in Chinese subjects, but parameters including WC were not used in this study, since

Table 4 Parameters' Odds ratio of MetS in both sexes using the lowest quartile as the reference

\begin{tabular}{|c|c|c|c|c|c|c|}
\hline \multicolumn{4}{|c|}{ Men } & \multicolumn{3}{|c|}{ Women } \\
\hline Disorder & wald $X^{2}$ & OR(95\% Cl) & $p$ value & wald $X^{2}$ & OR(95\% Cl) & $p$ value \\
\hline Age & 0.142 & $0.920(0.595-1.422)$ & 0.706 & 10.666 & $2.701(1.488-4.903)$ & 0.001 \\
\hline BMI ( $\geq 24)$ & 3.951 & $4.783(1.022-22.381)$ & 0.047 & 9.854 & 4.082(1.696-9.822) & 0.002 \\
\hline BF\% (>25 or 30$)$ & 0.149 & $0.871(0.431-1.760)$ & 0.700 & 1.037 & 0.570(0.193-1.682) & 0.308 \\
\hline $\mathrm{TC}(\geq 5.71)$ & 0.051 & $1.060(0.638-1.762)$ & 0.822 & 0.039 & $0.917(0.388-2.165)$ & 0.843 \\
\hline $\operatorname{LDL}(\geq 4.14)$ & 3.590 & $0.517(0.261-1.023)$ & 0.058 & 0.676 & $0.595(0.173-2.051)$ & 0.411 \\
\hline CRP (quartile) & 40.434 & $1.844(1.527-2.227)$ & 0.000 & 25.384 & $2.084(1.566-2.774)$ & 0.000 \\
\hline Exercise status & 0.494 & $0.849(0.538-1.341)$ & 0.482 & 3.655 & $1.835(0.985-3.419)$ & 0.056 \\
\hline Smoking status & 0.012 & $0.978(0.649-1.473)$ & 0.914 & 2.345 & $1.819(0.846-3.914)$ & 0.126 \\
\hline
\end{tabular}


Table 5 Sensitivity, specificity and AUC of cutoff value of three indicators in prediction of MetS

\begin{tabular}{|c|c|c|c|c|c|c|}
\hline Indicators & Cutoff value & Sensitivity & Specificity & AUC & $95 \% \mathrm{Cl}$ & $P$ value \\
\hline \multicolumn{7}{|l|}{$\mathrm{BMI}\left(\mathrm{kg} / \mathrm{m}^{2}\right)$} \\
\hline Men & 27.45 & 0.806 & 0.843 & 0.904 & $0.882 \sim 0.925$ & 0.000 \\
\hline Women & 23.85 & 0.927 & 0.729 & 0.898 & $0.869 \sim 0.928$ & 0.000 \\
\hline \multicolumn{7}{|l|}{$\mathrm{BF}(\%)$} \\
\hline Men & 23.95 & 0.841 & 0.778 & 0.883 & $0.859 \sim 0.908$ & 0.000 \\
\hline Women & 31.35 & 0.771 & 0.814 & 0.855 & $0.818 \sim 0.892$ & 0.000 \\
\hline \multicolumn{7}{|l|}{$\mathrm{FMI}\left(\mathrm{kg} / \mathrm{m}^{2}\right)$} \\
\hline Men & 7.00 & 0.802 & 0.869 & 0.920 & $0.900 \sim 0.940$ & 0.000 \\
\hline Women & 7.90 & 0.789 & 0.857 & 0.898 & $0.869 \sim 0.927$ & 0.000 \\
\hline
\end{tabular}

WC is a part of the definition of metabolic syndrome. BMI is an anthropometric parameter which is widely used to the assessment of obesity, and it is easily calculated. However, it cannot reflect body fat mass and body fat distribution due to the differences of age, sex and ethnic groups and obese types when BMI is used alone. Although some studies [10,31] found that high BF\% was associated with increased cardiovascular risk regardless of BMI whose categorization resulted in an underestimation of subjects with cardiovascular risk factors [32], people with the same BMI or the same percentage may have very different body composition, which may result in people with the same BMI or percentage of body fat exposing to different metabolic conditions, therefore, it is better to measure and express body composition as FMI and FFMI than either BMI or BF\% [33]. Among the indicators used to predict the presence of metabolic syndrome, FMI was the index that showed the greatest area under the ROC curve. In addition,our study showed that high FMI had significantly higher Odds ratio for metabolic syndrome than the low FMI in both sexes, which

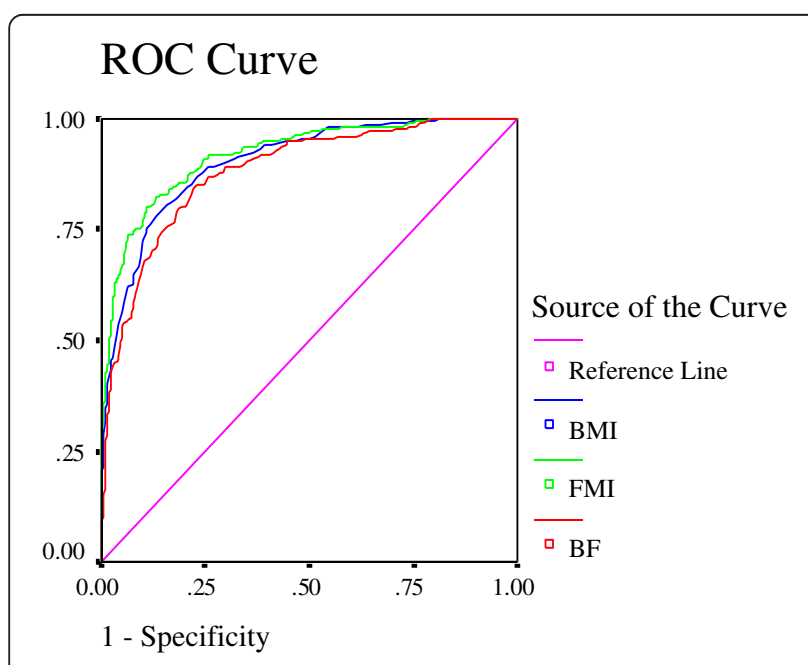

Figure 2 Receiver-operating characteristic(ROC) analysis of BMI, $\mathrm{BF} \%$, and $\mathrm{FMI}$ as indicators to predict MetS in men. was similar to one previous study [33], in which body composition was measured by DXA. Our study also showed that high FMI level was strongly associated with the presence of MetS after adjusting BMI and BF\% in both men and women, and the adjusted odds ratios of the risk of MetS were higher than that of $\mathrm{BMI}$ and $\mathrm{BF} \%$. Moreover, when WC was also added into regression analysis the $3^{\text {rd }}$ and $4^{\text {th }}$ quartiles of FMI for men and the $4^{\text {th }}$ quartile of FMI for women still had significantly higher Odds ratio for metabolic syndrome than the lowest quartile.

Therefore,our study shows that high FMI level appears to be independently associated with MetS regardless of BMI and BF\% and can be the effective measurement method for the assessment of metabolic syndrome in clinical practice. FMI of $7.00 \mathrm{~kg} / \mathrm{m}^{2}$ for men and $7.90 \mathrm{~kg} / \mathrm{m}^{2}$ for women by BIA could effectively predict the presence of MetS in our study. A recent study [34] showed that waistto-height ratio, which was a better screening tool than BMI and waist circumference for adult metabolic risk factors demonstrated in a recent systematic review [35], was the best screening tool for evaluation MetS in Korean men,

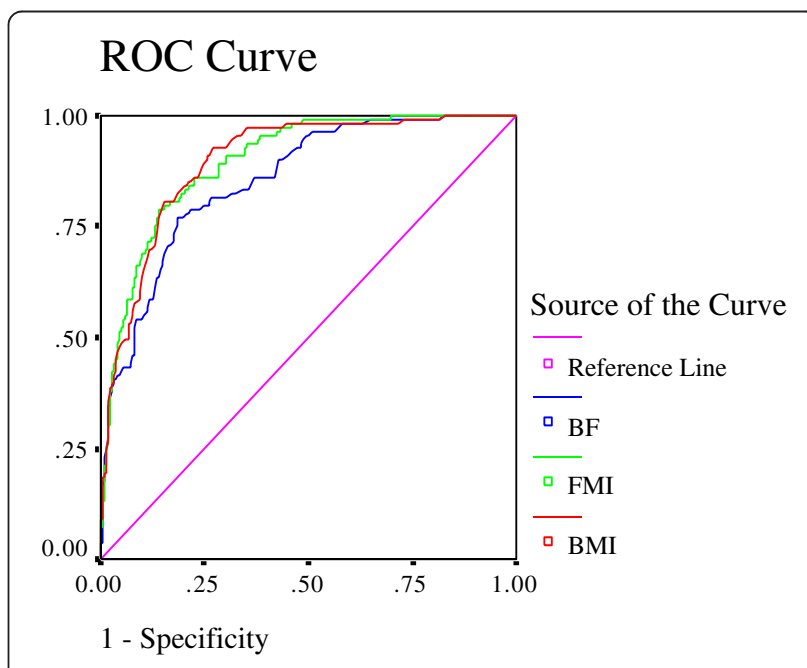

Figure 3 Receiver-operating characteristic(ROC) analysis of BMI, $\mathrm{BF} \%$, and $\mathrm{FMI}$ as indicators to predict MetS in women. 
and adding FMI could result in a modest increase in integrated discrimination improvement. Data analysis for the combination of waist-to-height ratio with FMI are not shown in this study, further investigation should be conducted with the aim at determining whether the combination is appropriate for Chinese population.

In addition, our study determined that the CRP level were significantly higher in postmenopausal women with MetS than those without MetS and higher CRP level is independent factor for the presence of metabolic syndrome, which is consistent with one recent study [36]. In addition, the mean age was significantly higher in MetS group than in non-MetS group $(52.25 \pm 9.56$ vs. $45.15 \pm 10.63, \mathrm{P}<0.001)$ and age seemed to be one of the risk factors of the presence of MetS in women, the possible reason was that postmenopausal women were occupational in the MetS group, and postmenopausal women are likely to have the increasing prevalence of insulin resistance and obesity (particularly visceral adiposity), which might contribute to the risk of MetS [14].

This study has several limitations. First, due to the cross-sectional design, it is not possible to explore the causal relationship between body composition and metabolic syndrome. Second, our population is restricted to 20-79-year-old men and women living in Beijing,and the result from oue study might not be applicable to other population. Third, hypertriglyceridemia, Low HDL-c, fasting hyperglucemia did not be included in the regression analysis, because they are the essential criteria in the diagnosis for MetS. Fourth, the prevalence of metabolic syndrome with age group (particularly in women since the post-menopause status might contribute to the risk of MetS due to the excessive fat accumulation) was not mentioned in this article, and further investigation should be performed in the future studies.

\section{Conclusion}

Despite these limitations, our study suggested that FMI seems to be a better indicator in the screening of the presence of metabolic syndrome than BMI and percentage of body fat in men and women.

\begin{abstract}
Abbreviations
MetS: Metabolic syndrome; BMI: Body mass index; WC: Waist circumference; SBP: Systolic blood pressure; DBP: Diastolic blood pressure; TC: Total cholesterol; TG: Triglyceride; HDL-C: High-density-lipoprotein cholesterol; LDL-C: Low-density-lipoprotein cholesterol; FBG: Fasting blood glucose; CRP: C-reactive protein; BF\%: Percentage of body fat; FMI: Fat mass index.
\end{abstract}

\section{Competing interests}

The authors declare that they have no competing interests.

\section{Authors' contributions}

MF was responsible for the study design. LPJ participated in the design of the study and drafted the manuscript. LHP participated in the sequence alignment. LYP performed the statistical analysis. All authors read and approved the final manuscript.

\section{Acknowledgements}

We thank all of the participants. We gratefully acknowledge the Department of Medical examination center, Peking Union Medical College Hospital, China Academic Medical Science and Peking Union Medical College.

\section{Author details}

${ }^{1}$ Department of Clinical Nutrition, Peking Union Medical College Hospital, China Academic Medical Science and Peking Union Medical College, Beijing 100730, China. ${ }^{2}$ Department of Medical examination center, Peking Union Medical College Hospital, China Academic Medical Science and Peking Union Medical College, Beijing 100730, China. ${ }^{3}$ No.1 ShuaiFuyuan, Wang Fujing ST, Dongcheng District, Beijing 100730, China.

Received: 22 April 2013 Accepted: 2 July 2013

Published: 3 July 2013

\section{References}

1. Reaven GM: Insulin resistance: the link between obesity and cardiovascular disease. Endocrinol Metab Clin North Am 2008, 37:581-601.

2. Mokdad AH, Bowman BA, Ford ES, Vinicor F, Marks JS, Koplan JP: The continuing epidemics of obesity and diabetes in the United States. JAMA 2001, 286:1195-1200.

3. Lavie CJ, Milani RV, Ventura HO: Obesity and cardiovascular disease: risk factor, paradox, and impact of weight loss. J Am Coll Cardiol 2009, 53:1925-1932

4. Lavie CJ, De Schutter A, Patel D, Artham SM, Milani RV: Body composition and coronary heart disease mortality: an obesity or a lean paradox? Mayo Clinic Proc 2011, 86:857-864.

5. Lavie CJ, Milani RV, Ventura HO, Romero-Corral A: Body composition and heart failure prevalence and prognosis: getting to the fat of the matter in the "obesity paradox". Mayo Clin Proc 2010, 85:605-608.

6. Romero-Corral A, Montori VM, Somers VK, Korinek J, Thomas RJ, Allison TG, Mookadam F, Lopez-Jimenez F: Association of bodyweight with total mortality and with cardiovascular events in coronary artery disease: a systematic review of cohort studies. Lancet 2006, 368:666-678.

7. Thibault R, Pichard C: The evaluation of body composition: a useful tool for clinical practice. Ann Nutr Metab 2012, 60:6-16.

8. Madeira FB, Silva AA, Veloso HF, Goldani MZ, Kac G, Cardoso VC, Bettiol H, Barbieri MA: Normal Weight Obesity Is Associated with Metabolic Syndrome and Insulin Resistance in Young Adults from a Middle-Income Country. PLoS One 2013, 8:e60673.

9. Lavie CJ, De Schutter A, Patel DA, Romero-Corral A, Artham SM, Milani RV: Body composition and survival in stable coronary heart disease-Impact of lean mass index and body fat in the "obesity paradox". J Am Coll Cardiol 2012, 60:1374-1380.

10. Zeng Q, Dong SY, Sun XN, Xie J, Cui Y: Percent body fat is a better predictor of cardiovascular risk factors than body mass index. Braz J Med Biol Res 2012, 45:591-600.

11. Deurenberg-Yap M, Chew SK, Deurenberg P: Elevated body fat percentage and cardiovascular risks at low body mass index levels among Singaporean Chinese, Malays and Indians. Obes Rev 2002, 3:209-215.

12. Cruz P, Johnson BD, Karpinski SC, Limoges KA, Warren BA, Olsen KD, Somers VK, Jensen MD, Clark MM, Lopez-Jimenez F: Validity of weight loss to estimate improvement in body composition in individuals attending a wellness center. Obesity (Silver Spring) 2011, 19:2274-2279.

13. Wright CM, Sherriff A, Ward SC, McColl JH, Reilly JJ, Ness AR: Development of bioelectrical impedance-derived indices of fat and fat-free mass for assessment of nutritional status in childhood. Eur J Clin Nutr 2008, 62:210-217.

14. Bintvibok W, Cbaikittisilpa S, Panyakamlerd K, Jaisamrarn U, Taecbakraicbana $\mathrm{N}$ : Cut-off value of body fat in association with metabolic syndrome in Thai peri- and postmenopausal women. Climacteric 2013, 16:1-5.

15. Jeong DLS, Min H, Kim Y, Choi S, Kim Y: Measuring performance evaluation of body fat measuring instrument applying body measuring value method. Korean J Health Promot Dis Prev 2006, 6:79-87.

16. Bolanowski M, Nilsson BE: Assessment of human body composition using dual-energy $\mathrm{x}$-ray absorptiometry and bioelectrical impedance analysis. Med Sci Monit 2001, 7:1029-1033.

17. Xu L, Cheng X, Wang J, Cao Q, Sato T, Wang M, Zhao X, Liang W: Comparisons of body-composition prediction accuracy: a study of 2 bioelectric impedance consumer devices in healthy Chinese persons using DXA and MRI as criteria methods. J Clin Densitom 2011, 14:458-464. 
18. Ellis KJ, Abrams SA, Wong WW: Monitoring childhood obesity: assessment of the weight / height index. Am J Epidemiol 1999, 150:939-946.

19. Schooling CM, Thomas GN, Leung GM, Ho SY, Janus ED, Lam TH: Is height associated with cardiovascular risk in Chinese adults? Epidemiology 2007, 18:274-278

20. Wells JC: A critique of the expression of paediatric body composition data. Arch Dis Child 2001, 85:67-72.

21. Vanltallie TB, Yang MU, Heymsfield SB, Funk RC, Boileau RA: Heightnormalized indices of the body's fat-free mass and fat mass: potentially useful indicators of nutritional status. Am J Clin Nutr 1990, 52:953-959.

22. Kyle UG, Schutz Y, Dupertuis YM, Pichard C: Body composition interpretation. Contributions of the fat-free mass index and the body fat mass index. Nutrition 2003, 19:597-604.

23. Kyle UG, Morabia A, Schutz Y, Pichard C: Sedentarism affects body fat mass index and fat-free mass index in adults aged 18 to 98 years. Nutrition 2004, 20:255-260.

24. Schutz $Y$, Kyle UU, Pichard C: Fat-free mass index and fat mass index percentiles in Caucasians aged 18-98 y. Int J Obes Relat Metab Disord 2002, 26:953-960.

25. Grundy SM, Cleeman JI, Daniels SR, Donato KA, Eckel RH, Franklin BA, Gordon DJ, Krauss RM, Savage PJ, Smith SC Jr, Spertus JA, Costa F: Diagnosis and management of the metabolic syndrome: an American Heart Association/National Heart, Lung, and Blood Institute Scientific Statement. Circulation 2005, 112:2735-2752.

26. Bei-Fan Z: Predictive values of body mass index and waist circumference for risk factors of certain related diseases in Chinese adults: study on optimal cut-off points of body mass index and waist circumference in Chinese adults. Biomed Environ Sci 2002, 15:83-96.

27. Lopez AD: Assessing the burden of mortality from cardiovascular diseases. World Health Stat Q 1993, 46:91-96.

28. Dongfeng G, Kristi R, Xigui W, Jing C, Xiufang D, Reynolds RF, Whelton PK Jiang H, InterASIA Collaborative Group: Prevalence of the metabolic syndrome and overweight among adults in China. Lancet 2005, 365:1398-1405.

29. Li Cl, Kardia SL, Liu CS, Lin WY, Lin CH, Lee YD, Sung FC, Li TC, Lin CC: Metabolic syndrome is associated with change in subclinical arterial stiffness: a community-based Taichung community health study. BMC Publ Health 2011, 11:808

30. Liu Y, Tong G, Tong $W$, Lu L, Qin X: Can body mass index, waist circumference, waist-hip ratio and waist-height ratio predict the presence of multiple metabolic risk factors in Chinese subjects? BMC Publ Health 2011, 11:35.

31. Cho YG, Song HJ, Kim JM, Park KH, Paek YJ, Cho JJ, Caterson I, Kang JG: The estimation of cardiovascular risk factors by body mass index and body fat percentage in Korean male adults. Metabolism 2009, 58:765-771.

32. Gómez-Ambrosi J, Silva C, Galofré JC, Escalada J, Santos S, Millán D, Vila N, Ibañez P, Gil MJ, Valentí V, Rotellar F, Ramírez B, Salvador J, Frühbeck G: Body mass index classification misses subjects with increased cardiometabolic risk factors related to elevated adiposity. Int $J$ Obes (Lond) 2012, 36:286-294.

33. Wang J, Rennie KL, Gu W, Li H, Yu Z, Lin X: Independent associations of body-size adjusted fat mass and fat-free mass with the metabolic syndrome in Chinese. Ann Hum Biol 2009, 36:110-121.

34. Kim JY, Oh S, Chang MR, Cho YG, Park KH, Paek YJ, Yoo SH, Cho JJ, Caterson ID, Song HJ: Comparability and utility of body composition measurement vs. anthropometric measurement for assessing obesity related health risks in Korean men. Int J Clin Pract 2013, 67:73-80.

35. Ashwell M, Gunn P, Gibson S: waist-to-height ratio is a better screening tool than waist circumference and BMI for adult cardiometabolic risk factors:systematic review and meta-analysis. Obesity Comorbidity Diagnostic 2012, 13:275-286.

36. Yang $\mathrm{T}$, Chu CH, Hsieh PC, Hsu CH, Chou YC, Yang SH, Bai CH, You SL, Hwang LC, Chung TC, Sun CA: C-reactive protein concentration as a significant correlate for metabolic syndrome:a Chinese population-based study. Endocrine 2013, 43:351-359.

doi:10.1186/1471-2458-13-629

Cite this article as: Liu et al:: The utility of fat mass index vs. body mass index and percentage of body fat in the screening of metabolic syndrome. BMC Public Health 2013 13:629.

\section{Submit your next manuscript to BioMed Central and take full advantage of:}

- Convenient online submission

- Thorough peer review

- No space constraints or color figure charges

- Immediate publication on acceptance

- Inclusion in PubMed, CAS, Scopus and Google Scholar

- Research which is freely available for redistribution 